DOI: $10.17516 / 1997-1370-0727$

УДК 316.483:378(4706)

\title{
Comparison of the Attitudes of Dagestani and the Krasnodar Region Students to Mediated Conflict Resolution
}

\author{
Galina P. Rogochaya and Elena V. Ulko* \\ Kuban State University \\ Krasnodar, Russian Federation
}

Received 20.01.2021, received in revised form 12.02.2021, accepted 09.03.2021

\begin{abstract}
The article presents the results of a socio-psychological study of students' mindsets about mediated conflict resolution. By such mindsets, we understand a systematic development of personal readiness to conflict situations that involve the idea of a possible conflict resolution method, attitude and evaluation of such methods, as well as the readiness of implementing them in certain conflict situations with the help of different categories of intermediaries (including mediators).

Empirical study sample: 159 university students (77 from Dagestan and 82 from the Krasnodar Region). Methods of empirical research: «The Thomas-Kilmann Conflict Mode Instrument (TKI)» (adaptation by N.V. Grishina); interview; questioning; list of personality traits of a mediator. Statistical methods: descriptive statistics, comparison method (Student's t-test).

The substantive differences in the cognitive, emotional and behavioural components of attitudes towards conflict resolution of the respondents of the compared groups were revealed. The Krasnodar Region students demonstrated the ability of independent conflict resolution, low importance of the social context, lack of understanding of the cultural mediation traditions, and a willingness to turn to professional mediators. Dagestani students are characterized by knowledge of traditional mediation practices and low readiness to turn to professional mediators. The role of the social environment and the social status of a mediator for them is high.

The culturally determined preferences of different types of mediators in different conflict situations, the specificity of the students' expectations of the mediator's personality, his psychological and professional characteristics were revealed.

The achieved results can be used to consider the ethnocultural properties of the conflict parties in the professional activities of mediators, their training and education. The research results can be also used for the organization and operation of mediation and psychological services at universities.
\end{abstract}

Keywords: conflict, ethnopsychology of conflict, social attitudes, attitudes of young people towards conflict resolution, mediation.

\footnotetext{
(C) Siberian Federal University. All rights reserved

* Corresponding author E-mail address: rogochayagp@rambler.ru, elulko@gmail.com ORCID: 0000-0003-4775-2958 (Rogochaya)
} 
Research area: pedagogy.

Citation: Rogochaya, G.P., Ulko, E.V. (2021). Comparison of the attitudes of Dagestani and the Krasnodar Region students to mediated conflict resolution. J. Sib. Fed. Univ. Humanit. Soc. Sci., 14(3), 363-374. DOI: 10.17516/1997-1370-0727.

\title{
Сравнение установок на урегулирование конфликтов с участием медиатора студенческой молодежи Республики Дагестан и Краснодарского края
}

\author{
Г.П. Рогочая, Е.В. Улько \\ Кубанский государственный университет \\ Российская Федераџия, Краснодар
}

Аннотация. В статье представлены результаты социально-психологического исследования установок студенческой молодежи на урегулирование конфликтов с участием посредников. Под данными установками мы понимаем системное образование готовности личности к участию в конфликтном взаимодействии, включающее представление о возможных путях урегулирования конфликтов, отношение и оценку данных способов, а также готовность их реализовывать в определенных конфликтных ситуациях с участием различных категорий посредников (в том числе медиаторов).

Выборка исследования: 159 студентов вузов (77 из Дагестана и 82 из Краснодарского края). Методы сбора эмпирических данных: опросник «Методика диагностики предрасположенности личности к конфликтному поведению» К. Томаса (адаптация Н.В. Гришиной); интервью; анкета для выявления содержания компонентов установки на урегулирование конфликта с участием посредников; список качеств личности посредника (медиатора) для ранжирования. Методы статистической обработки: описательная статистика, метод сравнения (t-критерий Стьюдента).

Обнаружены содержательные различия когнитивного, эмоционального и поведенческого компонентов установок на урегулирование конфликтов респондентов сравниваемых групп. Для краснодарских студентов характерна большая склонность к диалоговым способам поведения в конфликте, направленность на индивидуальные усилия по урегулированию ситуации, низкий уровень ориентированности на социальный контекст, отсутствие представлений о культурных традициях посредничества, готовность обращения к профессиональным посредникам. Для студентов из Дагестана характерна высокая информированность о традиционных практиках посредничества в конфликторазрешении. Высока роль социально значимого окружения, ориентированность на социальные статус и репутационную позицию посредника в сообществе, невысокая готовность обращения к профессиональным посредникам. Выявлены культурно обусловленные предпочтения обращения к разным типам посредников в связи с характером конфликтов. Определена специфика ожиданий студенческой молодежи Дагестана и Краснодарского края относительно личности посредника (медиатора), его психологических и профессиональных характеристик. Полученные результаты могут быть использованы в профессиональной 
деятельности посредников (медиаторов, психологов, юристов, педагогов и др.) для учета этнокультурной специфики участников конфликтов, при подготовке и обучении посредников, а также для организации и функционирования в вузах служб примирения (медиации), психологических служб.

Ключевые слова: конфликт, этнопсихология конфликта, социальные установки личности, установки молодежи на урегулирование конфликтов, медиация.

Научная специальность: 13.00.00 - педагогические науки.

\section{Введение в проблему исследования}

Возможность конструктивного разрешения конфликтов разного уровня является значимой социальной проблемой, решение которой связано с усилиями специалистов и ученых различных предметных областей. По мнению многих из них, в число востребованных профессий ближайшего будущего войдет профессия медиатора (Atlas novykh professiy, 2018). В нашей стране медиация находится в стадии институционального оформления, выступает одной из перспективных сфер профессиональной деятельности и областью развития новых социальных технологий. Полноценное и продуктивное внедрение медиации как практики урегулирования конфликтов должно основываться на всестороннем исследовании функционирования как самой процедуры, так и отношения различных социальных групп населения к участию в ней. Психологические аспекты посредничества и медиации изучены мало. По выражению О.В. Аллахвердовой, медиация - это, прежде всего, «новая коммуникативная практика в разрешении конфликтов», она не может быть эффективной без учета психологической составляющей конфликта и деятельности посредника (Allakhverdova, 2006: 41).

Включение медиации в жизнь современного российского общества должно происходить с учетом его неоднородности, сложного многонационального и поликонфессионального состава, строиться на знании культурного своеобразия и сложившихся традиций разрешения споров определенных социокультурных групп. В настоящее время в пространстве научных исследований по данной проблематике выделяют ряд направлений, изучающих осо- бенности конфликтов и медиации в поликультурной среде (Smolyaninova et al., 2018; Smolyaninova, 2020). Данные разработки актуальны как для Юга России в целом, так и для Краснодарского края в частности как региона с неоднородным культурным и этническим составом. Исследование этнокультурных практик урегулирования споров, исторического опыта примирительного правосудия горских народов Кавказа и Дагестана, в частности, нашли обобщающий анализ в работах Х. Магомедсалихова, А.Г. Мусаевой, И. Бабич (Musaeva， 2015; Traditsionnyye praktiki uregulirovaniya konfliktov, 2014). Возрождение института медиаторства и его актуальность изложены в широком обзоре исследований ежегодного семинара «Медиация и диалог на Южном Кавказе» (Mediation and dialogue in the South Caucasus, 2012).

Особый интерес для изучения представляет группа молодежи. Во многом это определяется социально-психологическим статусом данной группы, а также нарушенными механизмами интеграции и социализации, утраченными линейными моделями включения молодежи в общество с традиционными практиками (Cherkasova, 2004). Можно констатировать противоречие между поддержанием молодежью различных этнических групп сложившихся этнокультурных традиций урегулирования споров и наличием запроса на унифицированные, общеразделяемые несудебные процедуры эффективного разрешения конфликтов. В данной работе была поставлена задача психологического исследования и сравнения установок молодежи различных этнокультурных групп (Республика Дагестан и Краснодарский край) на урегулирование 
конфликтов с участием посредников. Мы изучали отношение молодежи, ожидания и готовность обращаться за помощью к различного рода посредникам: людям из их близкого круга общения, представителям традиционных практик посредничества, профессиональным специалистам по урегулированию конфликтов (юрист, психолог, медиатор). Решение данной задачи позволит расширить психологические возможности механизма регуляции и прогнозирования социального поведения. Даст возможность учитывать степень готовности, специфику определенных ожиданий различных групп молодежи для конструктивного влияния на процессы коммуникации и выстраивания диалоговых процедур. Повысит эффективность подготовки и внедрения института медиации как практики конфликторазрешения на основе знаний культурных установок и культурного своеобразия данной социальной группы.

\section{Концептологические основания исследования}

В настоящее время существует определенный массив исследований, ориентированных на изучение теоретических и прикладных аспектов медиации. Анализ публикаций показывает, что подавляющее большинство современных отечественных разработок посвящено юридическим аспектам медиации (А.С. Архипкина, А.Д. Карпенко, С.И. Калашникова, Ц.А. Шамликашвили и др.). Описание профессиональной деятельности медиатора и медиации как процесса осуществляется путем обозначения основных этапов медиативных переговоров, их содержания, действий медиатора и сторон на каждом из этапов (О.В. Аллахвердова, А.Г. Азарнова, А. Д. Осиновский и др.).

Психологические и психологопедагогические исследования в области медиации менее представлены (Е.Н. Иванова, Т. Ю. Базаров, А. С. Чиннова, О. Г. Смолянинова и др.). О.Г. Смолянинова акцентирует внимание на поликультурных аспектах медиации (Smolyaninova, 2018). Т. Ю. Базаров и А.С. Чиннова исследуют психологиче- ские аспекты успешности разрешения конфликта с использованием процедуры медиации. Они выделяют ряд определяющих факторов, которые структурируют следующим образом: профессионализм и личностные качества медиатора; специфика конфликта; особенности противоборствующих сторон (Bazarov, Chinnova, 2012). Наше внимание было сосредоточено на особенностях потенциальных участников медиативного процесса - молодежи разных этнических групп, их специфических установках и готовности к разрешению конфликта с помощью посредника, ожиданий от его психологических и профессиональных качеств. Мы исходили из представления о том, что стороны конфликта, кроме характеристик их ситуативных целей и имеющихся интересов, индивидуально-психологических особенностей, в процессе процедуры медиации будут проявлять некоторые общие установки конфликтного взаимодействия, связанные с их принадлежностью к социальным группам различной общности и уровня, в частности этнокультурной.

В нашей работе мы ориентировались на наиболее разделяемые научные взгляды на трактовку понятия «социальная установка» как в отечественной, так и в зарубежной науке. В психологии и социологии представлен ряд теоретических позиций. Наиболее разделяемым многими авторами является понимание социальной установки как готовности личности некоторым образом воспринимать и действовать по отношению к определенному объекту или ситуации, придающей данному виду активности устойчивый характер. Составляющие элементы установок представлены в структурных моделях, теории двухкомпонентной (Л. Терстоун, И. Сарнофф, Д. Кац) и трехкомпонентной социальной установки (М. Смит, К. Ховланд). Отвечая на вопрос о формировании установок личности, многие исследователи выделяют роль социального фактора. В рамках различных психологических направлений он представлен разнообразными процессами и механизмами в различных по масштабу и уровню социально-психологических образованиях, 
содержательно отнесенных к различным социальным пространствам.

Обращение к широкому социальному контексту, этнокультурной специфичности как фактору формирования социальных установок личности имеет научное обоснование и выраженный прикладной интерес (Ulko, 2019). В ряде работ этнические установки и стереотипы рассматриваются как модус проявления этничности (А.Г. Арутюнян, Л.М. Дробижева, С.Д. Гуриева, 3. Т. Гасанов, Б. А. Душкова, Т. Г. Стефаненко, В.А. Тишков и др.) (Rogochaya, Savva, Ulko, 2018).

Социальные установки и реализуемые в них ценности, традиции, поведенческие нормы определяют социальное поведение человека и служат системой ориентаций и регуляторов, позволяющих выстраивать целостную активность относительно разнообразных жизненных ситуаций. Поведение личности в конфликте, выбор стратегий взаимодействия в ситуации противоборства, готовность к определенным формам урегулирования и разрешения споров во многом определяются своеобразием социокультурных установок. Различия в установках могут быть описаны через особенности культуры. Из наиболее известных теорий, описывающих своеобразие культурных установок, можно выделить теорию высокои низкоконтекстуальных культур Э. Холла, теорию культурных измерений Г. Хофстеде и теорию культурной грамотности Э. Хирша (Model G. Hofstede..., 2010). В работах этих авторов и ряде других исследований выделяют особенности конфликтного взаимодействия и установок у представителей различных этнокультурных групп с опорой на социально-психологические характеристики культур (Matsumoto, 2012). Наиболее изученными являются вопросы соотношения избираемых представителями определенных социокультурных групп стратегий поведения с таким часто используемым измерением культуры, как индивидуализм/ коллективизм (Guriyeva, 2009; Matsumoto, 2012).

Этнические установки в отечественных исследованиях чаще всего рассматри- ваются либо в контексте межэтнических отношений, либо в контексте этнических стереотипов и предубеждений. В частности, Л.М. Дробижева рассматривает национальную установку в контексте национальной идентичности, готовности представителя определенной нации к своеобразному действию, поведению в межнациональных контактах (Drobizheva, 2010). B нашем исследовании мы акцентируем внимание не на вопросах межэтнического взаимодействия, а на проявлении этничности в области урегулирования человеком споров и конфликтов, возникающих в его повседневной жизни (Rogochaya, Savva, Ulko, 2018). В этом плане нам ближе позиция, в которой этнические установки рассматриваются как смысловые установки, вне зависимости от ситуативного контекста взаимоотношений (А.Г. Асмолов). Ориентируясь на классическую трехкомпонентную структуру установки, мы будем использовать понимание установки личности на разрешение конфликтных ситуаций как системное образование, включающее представление человека о возможных путях урегулирования конфликтов, отношение и оценку данных способов, а также готовность их реализовывать в определенных ситуациях конфликтного взаимодействия (Rogochaya, Ulko, 2019).

Для решения вопросов о проявлении своеобразия конфликтных установок личности, связанных с культурно обусловленными способами его регулирования, возможности обращения к посредникам, готовности представителей определенных этнокультурных групп участвовать в процедуре медиации, нами было проведено эмпирическое исследование. Его основной целью являлось психологическое изучение и сравнение установок на урегулирование конфликтов с участием посредников (в том числе медиатора) в группах студенческой молодежи Республики Дагестан и Краснодарского края. Основные решаемые эмпирические задачи: исследовать у респондентов сравниваемых групп общие установки на поведение в конфликте, выделив готовность к диалоговым способам поведения; 
определить знание и отношение респондентов к традиционным для их культуры социальным практикам урегулирования конфликтов; исследовать содержание когнитивной, эмоциональной и поведенческой компонент установок на урегулирование конфликтов с участием посредников; исследовать ожидания респондентов относительно личности посредника (медиатора), его психологических и профессиональных характеристик.

Методы сбора эмпирических данных: стандартизированный опросник «Методика диагностики предрасположенности личности к конфликтному поведению» К. У. Томаса (адаптация Н.В. Гришиной); анкета, разработанная нами для выявления содержания когнитивной, аффективной и конотативной компонент установки на конфликт и урегулирования конфликта с участием посредника; список качеств личности посредника (медиатора) для оценивания путем ранжирования. Вопросы анкеты и список качеств посредника формировались на основании предварительных интервью с представителями обеих групп сравнения. Методы статистической обработки результатов: описательная статистика, метод сравнения (t-критерий Стьюдента).

Характеристика выборки. В исследовании приняли участие студенты вузов в возрасте от 17 до 21 года (всего 159 чел.), из них 77 чел. (34 юноши и 43 девушки) из Дагестана (г. Махачкала) и 82 чел. (41 юноша и 41 девушка) из г. Краснодара. В выборке дагестанских студентов представлены коренные этносы Дагестана, в целом соответствующие национальному составу республики (34 аварца, 17 даргинцев, 6 лахсцев, 8 лезгин, 3 кумыка, 2 табасаранца, 1 еврей, 1 армянин, 1 немец, 1 ногаец, 3 без указания национальности). Студенты из Краснодара - 63 русских, 6 армян и единичные представители других национальностей. Эти данные имеют серьезные отклонения от средних по краю (русских 56,5 \% среди опрашиваемых студентов и 86,5 \% в общем составе населения).

Обратимся к основным результатам исследования. Сравнение полученных данных в выборках по методике «Диагностики предрасположенности личности к конфликтному поведению» К. Томаса позволяет выделить общие тенденции и специфику установок на поведение у студентов из Дагестана и Краснодара. Выявлены общие характеристики - ориентация на конструктивные способы поведения («сотрудничество», «компромисс»), средний уровень выбора пассивных форм реагирования («приспособление», «избегание») и наименьшее предпочтение «соперничество». Интерес представляют фиксируемые различия в выборках $(\mathrm{p} \leq 0,01)$. Что касается наименее привлекательной стратегии «соперничество», то у краснодарских студентов самый низкий средний показатель $(3,8)$, но при достаточно большом по сравнению с другими шкалами разбросе оценок (стд. откл. 3,02). У дагестанских студентов показатель по «соперничеству» значимо ниже $(2,6)$, чем у краснодарских. Но при этом они более единодушны в данной оценке. Это единственный параметр, по которому разброс данных (стд. откл. 2,40) наименьший по сравнению с другими шкалами и ниже, чем у группы сравнения. Отмеченный факт может свидетельствовать о том, что данная стратегия имеет негативную оценку, не является социально одобряемой, либо о том, что у данной социально-демографической группы недостаточно социальных ресурсов для использования этой стратегии. В пассивных формах реагирования у краснодарских респондентов преобладает «избегание» $(6,2)$ по сравнению с «приспособлением» $(5,1)$. Для дагестанских несколько предпочтительней «приспособление» $(5,0)$, чем «избегание» $(4,7)$. По стратегии «приспособление» показатели в краснодарской выборке выше относительно дагестанской. На основании анализа величин стандартных отклонений по всем шкалам, кроме «соперничества», респонденты из Дагестана демонстрируют больший разброс ответов, чем краснодарские. Несмотря на склонность респондентов обеих групп к диалоговым формам взаимодействия, средние показатели по шкалам «компромисс» (7,6 краснодарские и 5,5 дагестан- 
ские) и «сотрудничество» $(6,5$ и 5,2 соответственно) имеют значимые различия $(\mathrm{p} \leq 0,01)$. Данный факт свидетельствует о более выраженной склонности краснодарских студентов обращаться к диалогу в конфликтном взаимодействии. Исходя из того, что методика определяет сознательно определяемую предрасположенность личности к определенному виду поведения, полученные данные мы не можем интерпретировать как фиксацию реальных форм поведения респондентов в конфликте.

Рассмотрим результаты исследования установок молодежи на выбор посредника в урегулировании конфликтов, полученные с помощью разработанной анкеты. Вопросы анкеты были организованы в соответствии с трехкомпонентной моделью социальной установки. В блоке когнитивной компоненты вопросы касались общей направленности на урегулирование споров с участием разного рода посредников, осведомленность о соответствующих процедурах и конкретно о медиации, знание культурных традиций в этой области отношений. В аффективном блоке определяли отношение к процедуре посредничества, содержание психологического образа посредника, отношение респондентов к его личностным и профессиональным качествам и деятельности, отношение к мнению социального окружения относительно поведения в конфликте, важности учета культурных традиций. В поведенческой составляющей установке мы выявляли готовность обратиться к посреднику при урегулировании конфликтов в различных сферах жизни, наличие и характер такого опыта, готовность прибегнуть в процедуре медиации. Ответы респондентов уточняли в выборочных интервью.

Обратимся к наиболее существенным результатам. Интерес представляет выделение респондентами возможных посредников в урегулировании конфликтов. В общем плане отметим более высокую частоту готовности к обращению к различным посредникам у краснодарских респондентов. Краснодарские студенты отметили большую осведомленность о деятельности профессиональных посредников. Существенные различия были выявлены при сравнении знаний культурных традиций урегулирования споров. Не знакомыми с культурными традициями и назвавшими только формально-юридические процедуры урегулирования оказались 95 \% краснодарских респондентов. Из выборки дагестанских респондентов $50 \%$ проявили знание ряда традиций и принципов, характерных для их этнокультурной общности. Для них также значима включенность социального контекста в урегулирование конфликтов. Мнение окружающих, родственников, сохранение своей репутации существенным образом влияют на поведение в конфликте. Для $21 \%$ краснодарских респондентов мнение окружающих является значимым фактором, важной составляющей для понимания ситуации и ее конструктивного урегулирования («мне важен взгляд со стороны для более правильного урегулирования конфликта»). Вместе с тем большое количество ответов носило явно негативную оценку учета мнения окружающих («окружающих не должно волновать, каким образом будет решен конфликт», «совсем не имеет значения, что думают другие»). Такие индивидуально-ориентированные ответы в выборке дагестанских студентов были единичными. Это может свидетельствовать о горизонтальном коллективизме как о культурной установке. Для студентов из Краснодара характерна установка на индивидуальную линию урегулирования конфликта и намерение противостоять влиянию социального окружения.

Были выявлены различия в готовности обращения к разным посредникам в связи с конфликтами разного рода. Данные по обеим выборкам (при некотором преобладании у краснодарских студентов) демонстрируют склонность молодых людей обращаться за помощью в урегулировании конфликтов к своему ближайшему окружению - семье и друзьям. Отличия представляют позиции выборок по вопросам регулирования конфликтов с родственниками. Дагестанские студенты в редких случаях (7 \%), краснодарские чаще (32\%) обраща- 
ются за помощью к друзьям при конфликтах с родственниками. Конфликты с родственниками и соседями решаются ими преимущественно в кругу семьи (54 и $40 \%$ ).

Дагестанские студенты в решении всех видов конфликтов, кроме учебы, в большей степени, чем краснодарские, склонны обращаться к религиозным авторитетам и представителям общественности. Особо это проявляется относительно урегулирования конфликтов с представителями другой культуры $(17,7 \%)$, в вопросах урегулирования конфликтов с родственниками $(12,9 \%)$ и соседями $(6,9 \%)$. Краснодарские студенты практически не готовы обращаться за помощью к священнику в урегулировании конфликтов (3,2 \%). Однако немногочисленные респонденты с такой установкой предметом обсуждения считают практически все виды конфликтов в равной степени.

Готовность обратиться к профессиональным посредникам (психолог, юрист, медиатор) более выражена в краснодарской выборке. Студенты дифференцированно подходят к выбору специалиста в связи с характером конфликта. У психолога готовы урегулировать преимущественно конфликты с родственниками $(17,9 \%)$. К юристу обратятся с конфликтами на работе (21\%) и соседями (11\%). Обращение к медиатору больше связывают с разрешением рабочих конфликтов $(16,4 \%)$ и с проблемами отношений с представителями другой культуры $(18,8$ \%). Для группы дагестанских студентов характерна более низкая готовность пользоваться услугами профессиональных посредников для урегулирования споров. Они практически не готовы обращаться за помощью к юристам, за исключением конфликтов на работе $(19,7$ \%). Несколько выше готовность обращаться за помощью к психологу. Среди всех указанных видов конфликтов к психологу они обратятся в случае конфликтов с родственниками (8\%).

Для нас особый интерес представлял вопрос о понимании респондентами профессиональной деятельности медиатора и готовности решать споры с его участием. Краснодарские студенты практически втрое чаще обозначают свою осведомленность о профессиональной деятельности медиатора (27,8 и 10,7 \%). При этом респонденты обеих групп проявили близкую степень заинтересованности в получении опыта работы с медиатором (20,6 \% дагестанские и 22,5 \% краснодарские). Такая возможность больше радует краснодарцев (18,8 и $12 \%$ соответственно). Настороженное $(6,0$ и $4,1 \%)$ и негативное отношение $(6,9$ и 4,0 \%) менее выраженно, однако эти варианты чаще встречаются в группе дагестанских студентов.

Практически треть респондентов из каждой выборки обозначили возможность общения с медиатором в будущем. Разница позиций демонстрируется в ответах по готовности обратиться в данный момент. Студенты из Краснодара более чем в два раза чаще видят реальной текущую возможность обращения к медиатору (18 и $8 \%$ соответственно). Явное отрицание такого варианта обозначили 18,8 \% дагестанских студентов и 9,8 \% краснодарских. Эти показатели соотносятся с характером информированности и отношения к медиатору: более низкая информированность о деятельности медиатора среди дагестанских студентов вызывает более настороженное отношение к возможности прибегнуть к его помощи.

Готовность к участию в процедуре медиации во многом связана с ожиданиями, предъявляемыми к личности медиатора. Мы установили ожидания к его профессиональной подготовке, к профессиональным и личностным характеристикам.

Выявлены различия ответов респондентов сравниваемых выборок относительно профессиональной подготовки медиатора. Для студентов из Дагестана специальная профессиональная подготовка не важна. Респонденты обозначали наличие у медиатора других видов образования и знаний как фактора успешности его деятельности. Для студентов из Дагестана в первую очередь необходимо наличие религиозного образования $(41,0 \%)$, знание культурных традиций $(34,7 \%)$, психологическое образование $(29,8 \%)$ и наименее значимо юридическое 
(7,2 \%). Они демонстрировали знание сложившихся в их культуре институтов посредничества (чаще упоминают маслиат, шариат, совет старейшин и женщину, бросающую платок между спорящими), отмечали влияние религиозных норм на практику примирения. Респонденты подчеркивали, что формально-юридический подход к урегулированию споров является наименее предпочтительным, поскольку может свидетельствовать о «неумении договариваться, а это показатель, что ты не мужчина». Порядка $27 \%$ опрошенных настаивают на важности урегулирования споров в соответствии с их культурными традициями. Однако выражены и другие позиции. Около $34 \%$ считают, что традиции урегулирования можно не учитывать, важно, чтобы спор был решен, и не важно, каким образом. Часть респондентов (16 \%) отметили, что традиции у всех разные и лучше, чтобы процедура носила нейтральный характер. Обращение к традициям может только усугубить ситуацию.

Для респондентов из Краснодара ожидания от профессиональной подготовки медиатора выглядят иначе. На необходимость специальной профессиональной подготовки медиатора как значимого условия указали 54 \% респондентов. Более половины подчеркнули значимость для медиатора психологического образования (57,7 \%), далее примерно в равной степени знание культурных норм $(27,7 \%)$ и юридическое образование $(23,4 \%)$, практически неважным отмечено религиозное $(4,1 \%)$.

У респондентов сравниваемых выборок были установлены отличия в ожиданиях проявления медиатором определенных психологических характеристик. Им был предложен список личностных качеств, каждое из которых необходимо было оценить по пятибалльной шкале. Анализ семантического ядра списка качеств позволяет фиксировать определенные общие моменты и различия в ответах испытуемых. Для обеих групп нейтральность и справедливость медиатора являются его важными центральными характеристиками. Для краснодарских студентов значимыми качествами эффективного посредника служат его коммуникативные навыки и знания в области ведения переговоров. Приоритет отдан когнитивным характеристикам (умение работать с информацией, посмотреть на ситуацию со стороны, обозначить проблему в сложных ситуациях, четко формулировать высказывание, прогнозировать ситуацию, понять и рационально проанализировать ситуацию, понимать чужие эмоции, аргументировать и убеждать). Также значимыми являются такие характеристики эффективной коммуникации, как умение владеть собой, дипломатичность, умение слушать. Эмоциональный компонент слабо представлен в списке качеств посредника, за исключением таких качеств, как умение вызывать доверие, уравновешенность.

Дагестанские студенты особо важными для медиатора считают характеристики, связанные с проявлением эмоциональноотношенческого аспекта взаимодействия (способность вызывать доверие, обаяние и внешняя привлекательность, умение откликаться на эмоциональное состояние, управлять эмоциональным состоянием участников, уравновешенность, умение высказывать сочувствие и поддержку) и морально-нравственного (справедливость, порядочность, честность). Менее представленными оказались когнитивные характеристики (наблюдательность, умение понять и рационально анализировать ситуацию, умение аргументировать, красноречие - использование образов и метафор). Относительно эмоционального аспекта взаимодействия в конфликте можно выделить некоторое противоречие. Респонденты транслируют неприемлемость использования агрессивных форм взаимодействия и проявления эмоций при разрешении конфликтов. С другой стороны, они явно выражают ожидание, что медиатор сможет учесть эмоциональные проявления участников, выразит свое понимание и поможет справиться с деструктивными эмоциями.

В обеих группах присутствует значимость репутации медиатора. Но содержание данной характеристики имеет различный 
смысл. Для краснодарских респондентов это преимущественно относится к оценке в профессиональном пространстве, а для дагестанских - это позиция в локальном социальном сообществе.

\section{Заключение}

Представленные результаты эмпирического исследования свидетельствуют о ряде общих позиций и значимых различиях в установках на разрешение конфликтов с участием посредника в этнокультурных выборках студентов из Дагестана и Краснодара. При общей готовности молодежи обеих групп обращаться к посреднику при урегулировании конфликтов представления о том, кто может быть посредником в различных спорах, в культурных группах не всегда совпадают. Респонденты данной возрастной группы в большей степени проявляют установку обращаться к непосредственному ближайшему окружению (друзья, семья). Из профессиональных примирителей они отдают приоритет психологу. Этот факт и другие данные свидетельствует о важности для респондентов не формально-юридического, а личностнопсихологического, а для дагестанской молодежи и социально-отношенческого факторов при урегулировании конфликтов.

Для достижения решения задач нашего исследования стоит уделить внимание выявленным отличиям в установках сравниваемых групп. В отличие от краснодарских студентов, для которых профессиональные примирители являются популярным вариантом при урегулировании конфликтов, для дагестанских характерна готовность обращаться за помощью к религиозным деятелям и представителям своей общины. Они демонстрируют знания культурных традиций урегулирования споров, значимость коллективистских позиций, ориентированность на социальный контекст и отношения. Данный факт вполне соотносится с горизонтальным коллективизмом как общей культурной установкой в данной группе.

Относительно готовности решать споры с участием медиатора студенты из Крас- нодара оказались более осведомленными в данной области профессиональной деятельности, заинтересованными и готовыми уже сейчас воспользоваться такой возможностью. Эта установка проявляется несмотря на то, что для данной группы характерна более индивидуалистическая позиция, намерение самостоятельно вступать во взаимодействие с оппонентом и урегулировать конфликты. Видимо, такой вариант поведения трактуется ими скорее как собственная активность в нахождении решения, чем как использование ресурса третьей стороны. Дагестанские студенты заинтересованы и позитивно оценивают деятельность медиатора, но более осторожны и недоверчивы к такой практике, менее настроены на использование ее в своей жизни. Значимость психологического контекста взаимодействия при урегулировании конфликтов проявляется при анализе ожиданий молодежи от профессиональных и личностных характеристик медиатора. Для респондентов обеих выборок значимыми оказались качества посредника, характеризующие нейтральность его позиции, владение навыками коммуникации. Результаты демонстрируют ориентированность краснодарской выборки на профессиональную подготовку медиатора, его способности к высокопродуктивной интеллектуально-интерпретационной активности, возможности к выстраиванию эффективной коммуникации. Дагестанские студенты выражают ориентированность на способности медиатора выстраивать конструктивный процесс через учет эмоционального и отношенческого контекста взаимодействия участников, проявление нормативных морально-нравственных качеств и наличие репутационных позиций в социуме. Отмеченные особенности вписываются в общую систему культурных установок, соотносимых с использованием понятия высококонтекстуальной характеристики культуры в теории Э. Холла.

Обобщая результаты, можно отметить, что для краснодарских студентов характерно отношение к посреднику как к инструменту профессионального урегулирования споров. Личностные особенности 
посредника являются второстепенными, как и его социально-ролевая позиция и этнокультурная принадлежность. Для дагестанских студентов первостепенно важно, чтобы посредник был вписан в их привычный социальный контекст, был признанным авторитетом в локальном сообществе, знающим традиции урегулирования споров и способным руководствоваться ими при решении конкретного случая. Решение, принятое с его помощью (либо принятое посредником и обязательное для исполнения), должно быть одобряемо социальным окружением. С другой стороны, для них важно, чтобы контакт с посредником носил характер личностного общения, ориентированного не только на решение спора, но и на личностное принятие, поддержку и понимание.

Для дагестанских студентов более значимым является личностный аспект данного варианта социального взаимодействия.

Полученные нами результаты исследования свидетельствуют о нали- чии определенной специфики установок на урегулирование конфликта с участием посредников, готовности обратиться к различным посредникам и присутствии особых ожиданий от личности посредника у студенческой молодежи Дагестана и Краснодарского края. Данный факт позволяет говорить о наличии этнокультурной специфичности установок личности на урегулирование конфликтов с участием посредников, в частности медиатора. Внедрение практики медиаторства в нашу социальную реальность должно проходить постепенно и на базе понимания и учета сложившихся в обществе традиций, наличия определенных установок и ожиданий у участников процесса. Профессиональный посредник призван обеспечить пространство для взаимодействия равных, но во многом разных по своим установкам сторон. Знание этих различий, учет этнокультурного своеобразия могут позволить организовать этот процесс максимально эффективно.

\section{Список литературы / References}

Allakhverdova, O.V. (2006). Mediatsiia - novaya kommunikativnaia praktika v razreshenii konfliktov [Mediation is a new communicative practice in conflict resolution]. In Zhurnal sotsiologii i sotsial'noy antropologii [Journal of Sociology and Social Anthropology], 9(4), 31-49.

Atlas novykh professiy (2018). Available at: http://atlas100.ru/ (accessed 10.10.2018).

Bazarov, T. Yu., Chinnova, A.S. (2012). Sotsial'no-psikhologicheskiye determinanty effektivnosti mediatsii [Socio-psychological determinants of the effectiveness of mediation]. In Psikhologicheskiye issledovaniia [Psychological research], 5 (23), available at: http://psystudy.ru

Cherkasova, T.V. (2004). Conflict management in the youth environment as a social problem / Author's abstract of dissertation and author's abstract on the Higher Attestation Commission of the Russian Federation 22.00.08, for the degree of Doctor of Sociological Sciences. Available at: https://www.dissercat. $\mathrm{com} /$ content/upravlenie-konfliktami-v-molodezhnoi-srede-kak-sotsialnaya-problema_(accessed 27 October 2020).

Drobizheva, L.M (2010). Identichnost' i etnicheskiye ustanovki russkikh v svoyey i inoetnicheskoy srede [Identity and ethnic attitudes of Russians in their own and non-ethnic environmen]. In Sotsiologicheskiye issledovaniia [Sociological Research], 12, 49-58.

Gordeyeva, S.S. (2016). Sushchnost' i struktura sotsial'noy ustanovki v sotsiologii i sotsial'noy psikhologii [The essence and structure of social attitude in sociology and social psychology]. In Vestnik Permskogo universiteta. Filosofiia. Psikhologiia. Sotsiologiia [Bulletin of the Perm University. Philosophy. Psychology. Sociology], 3(27), 135-139.

Guriyeva, S.D. (2009). Ustanovka i formirovaniye sistemy mezhetnicheskikh otnosheniy [Installation and formation of a system of interethnic relations]. In Vestnik Nizhegorodskogo universiteta im. N.I. Lobachevskogo. Seriia Sotsiologiia. Psikhologiia. Filosofiia [Bulletin of the Nizhny Novgorod University. N. I. Lobachevsky. Sociology series. Psychology. Philosophy], 6(1), 282-291. 
Matsumoto, D. (2012). Psikhologiya i kul'tura: Sovrem. Issled [Psychology and culture: Let's talk. issled]. St. Petersburg, Praym-Yevroznak. Moscow, Neva, 414 p.

Mediation and dialogue in the South Caucasus (2012). Available at: https://www.internationalalert. org/sites/default/files/publications/201208MediationSCaucasusRu.pdf (accessed 27 October 2020).

Model G. Hofstede in the context: parameters of quantitative characteristics of culture (2010). Available at: http://lse2010.narod.ru/olderfiles/LSE2014pdf/LSE2014Hofstede.pdf (accessed 27 October 2020).

Musaeva, A.G. (2015). Conciliatory justice among the peoples of Dagestan. In Modern Problems of Science and Education, 1 (1), available at: https://www.science-education.ru/pdf/2015/1/8.pdf

Rogochaya, G.P., Ulko, E.V. (2019). Psychological analysis of youth attitudes towards resolving conflicts with the participation of mediators: ethnocultural aspect [Psikhologicheskiy analiz ustanovok molodezhi k razresheniyu konfliktov s uchastiyem posrednikov: etnokul'turnyy aspect]. In Konfliktologiya XXI veka. Puti i sredstva ukrepleniya mira: materialy Tret'yego Sankt-Peterburgskogo mezhdunarodnogo kongressa konfliktologov [Conflictology of the XXI century. Ways and means of strengthening peace: materials of the Third St. Petersburg International Congress of Conflictologists]. St. Petersburg, 304-307.

Rogochaya, G.P., Savva, E.V., Ulko, E.V. (2018). Etnichnost' kak kontekst konfliktnogo vzaimodeystviya: psikhologicheskiy i sotsial'no-politicheskiy aspekty [Ethnicity as a context of conflict interaction: psychological and socio-political aspects]. In Chelovek. Soobshchestvo. Upravleniye [Man. Community. Management], 19(1), 61-75.

Smolyaninova, O.G., Bezyzvestnykh, E.A., Korshunova, V.V., Popova, Iu.V. (2018). Mediativnyye praktiki v obrazovanii: polikul'turnyy kontekst [Mediation practices in education: a multicultural context]. Krasnoyarsk, Sib. feder. un-t, 272 p.

Smolyaninova, O.G (2020). Konflikty i mediatsiya v mul'tikul'turnom sotsiume: psikhologopedagogicheskiye i sotsiologicheskiye aspekty [Conflicts and mediation in a multicultural society: psychological, pedagogical and sociological aspects]. In Zhurnal SFU. Gumanitarnyye nauki [SibFU Journal. Humanitarian sciences], 13 (9), 1428-1434.

Traditsionnyye praktiki uregulirovaniya konfliktov / Materialy yezhegodnogo seminara 2010-2014 gg. (sbornik) [Traditional practices of conflict resolution / Materials of the annual seminar 2010-2014 (collection)] (2014). Moscow, MOO Tsentr «Sudebno-pravovaya reforma», $252 \mathrm{p}$.

Ulko, E.V. (2019). Attitudes towards conflict in the labor activity of young people at different stages of professionalization [Ustanovki k konfliktu v trudovoi deiatel'nosti molodezhi na raznykh stadiiakh professionalizatsii]. In Mirovoye razvitiye: problemy predskazuyemosti i upravlyayemosti / XIX Mezhdunarodnyyye Likhachevskiye nauchnyye chteniya 22-24 maya 2019 g. [World development: problems of predictability and controllability / XIX International Likhachev Scientific Readings May 22-24, 2019]. SPb, 602-604. 